\title{
Article
}

\section{An Employee Competency Framework in a Welfare Organization}

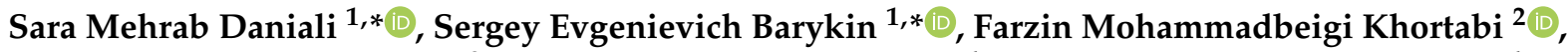 \\ Olga Vladimirovna Kalinina ${ }^{3}$, Olga Anatolievna Tcukanova ${ }^{4}$, Elena Konstantinovna Torosyan ${ }^{4}$, \\ Svetlana Poliakova ${ }^{5}$, Sergey Prosekov ${ }^{6}$, Nikita Moiseev ${ }^{7}\left[\right.$ and Tomonobu Senjyu ${ }^{8}$ (D)
}

1 Graduate School of Service and Trade, Peter the Great St. Petersburg Polytechnic University, 195251 St. Petersburg, Russia

2 Department of Theory and Organization of Management, State University of Management, 109542 Moscow, Russia; f_b258@yahoo.com

3 Graduate School of Industrial Management, Peter the Great St. Petersburg Polytechnic University, 195251 St. Petersburg, Russia; olgakalinina@bk.ru

4 Faculty of Technology Management and Innovation, ITMO University, 197101 St. Petersburg, Russia; zoa1999@mail.ru (O.A.T.); etorosyan@mail.ru (E.K.T.)

5 Department of Business Informatics, Financial University under the Government of Russian Federation, 197198 St. Petersburg, Russia; goodway@mail.ru

6 Faculty of Social Sciences and Mass Communications, Financial University under the Government of the Russian Federation, 124167 Moscow, Russia; ser.prosekov@ya.ru

7 Department of Mathematical Methods in Economics, Plekhanov Russian University of Economics, 117997 Moscow, Russia; mr.nikitamoiseev@gmail.com

8 Department of Electrical and Electronics Engineering, University of the Ryukyus, Okinawa 903-0213, Japan; b985542@tec.u-ryukyu.ac.jp

* Correspondence: sara_danial64@yahoo.com (S.M.D.); sbe@list.ru (S.E.B.)

check for

updates

Citation: Daniali, S.M.; Barykin, S.E.; Khortabi, F.M.; Kalinina, O.V.; Tcukanova, O.A.; Torosyan, E.K.; Poliakova, S.; Prosekov, S.; Moiseev, N.; Senjyu, T. An Employee Competency Framework in a Welfare Organization. Sustainability 2022, 14 , 2397. https://doi.org/10.3390/ su14042397

Academic Editor: Lucian-Ionel Cioca

Received: 12 January 2022

Accepted: 16 February 2022

Published: 19 February 2022

Publisher's Note: MDPI stays neutral with regard to jurisdictional claims in published maps and institutional affiliations.

Copyright: (c) 2022 by the authors. Licensee MDPI, Basel, Switzerland. This article is an open access article distributed under the terms and conditions of the Creative Commons Attribution (CC BY) license (https:// creativecommons.org/licenses/by/ $4.0 /)$.

\begin{abstract}
Purpose-The aims of the current study were as follows: (1) to develop a framework of the job competence of employees to examine the recruitment of employees in their specialized fields, and (2) to answer the question of whether the development of that framework of the job competence of employees in attracting and employing people or their appointment and promotion was effective in achieving the goals of the organization. Design/methodology-Researchers examined the work environment of a branch of the Welfare Organization of Iran and the most important duties and responsibilities of the employees of the specialized spheres of the organization. Afterward, researchers listed the essential knowledge, skills, and attitudes necessary for the employees. Then, the authors asked 70 experts working in this organization to express their views on the importance of each of these items and the status of each of the proposed items in terms of their relevance, clarity, simplicity, and ambiguity. Accordingly, the competencies were categorized and titled. The identified competencies were classified into four main groups: needs assessment, planning, implementation, and evaluation. The authors used the pairwise comparison method and the hierarchical analysis process approach to weighting. Findings-The authors set and presented critical competencies related to each specialized field of healthcare, social, educational, and cultural affairs in separate frameworks. The research results allowed theoretical and practical approaches to modeling to consider transversal and disciplinary competencies for a social, economic, or environmental commitment based on the sustainability concept. Value-Developing the employee competency frameworks of the health service is essential for sustainable development. The validated employee competency frameworks in the Welfare Organization can be applied in other provinces of Iran and other sectors of the healthcare system.
\end{abstract}

Keywords: work performance; competency framework; hierarchical analysis process

\section{Introduction}

The importance of competencies to human resource management has existed for years [1]. Currently, activities are carried out in the competency-based system approach to 
human resources. These activities affect various functions of human resource management, making this issue one of the strategic goals and objectives in the field of human resource management of organizations and institutions in developed and some developing countries. Therefore, the need for and importance of identifying the competencies required by human resources and formulating purposeful competency frameworks are increasingly emphasized by organizations.

The competency framework has been considered an adequate flow of human resources. In the early 1970s, the first competency framework was developed by McClelland [2], indicating that traditional assessments of intelligence, aptitude, and other conditions and characteristics, such as academic degrees, are not an excellent technique to predict job performance. In a case study, the selection of junior foreign service information officers was investigated. In that case, it was concluded that competencies such as interpersonal sensitivities, positive intercultural considerations, and managerial skills differentiated between prominent officers and ordinary intelligence officers. It was further proved that competency-based approaches were considered an essential tool in most organizational functions, such as human resource planning, succession plans, and employee behavior and performance [3].

The authors agree that in the paper, the topic that is most emphasized is the role of competencies, but a link should be made with the concept of inclusion described in works [4-6]. E. Engseth [5] offered as a topic for further research the need to develop cultural competency within the profession, with cultural competency considered as a framework for equity, diversity, and inclusion work. In the study of Mullin et al. [6], inclusion was defined as creating environments in which any individual or group can be and feel welcomed, respected, represented, supported, and valued to participate fully. An exciting issue could arise, making the logical bridge between organizational responsibility and leadership competency.

The extensive participation of employees, experts, and stakeholders, and establishing communication between them, are required to develop a competency framework, by creating a common consensus on and understanding of the concept of competencies, as well as precise and scientific processes for identifying and defining them.

Currently, the total population of Iran exceeds 83.5 million people. According to the Information Technology, Statistics and Computing Center of the Welfare Organization of Iran (WOI), by 2021 the share of various funds in the insurance coverage of the country were as follows: the share of the WOI of the total population covered was $76 \%$; the share of the National Pension Fund was 10\%; the share of the Social Insurance Fund of farmers, villagers, and nomads was $6 \%$; and the share of other funds was $8 \%$.

The Welfare Organization of Iran started working in 1979, with the merger of charitable and support organizations that operated in this sector, by adopting measures and providing non-insurance services and support, relying on public participation and the close cooperation of relevant organizations. The aims of this organization are to take steps to expand the rehabilitation, support, and prevention of disabilities and social harms, as well as to help meet the basic needs of low-income groups.

Currently, the WOI in its areas of activity faces various challenges and the spread of different phenomena that are referred to as social harms, including an increase in addiction and addicts; child abuse and neglect; prisoners; delinquency; aging and the number of the elderly; and the number of known disabled people and their requests for rehabilitation and social services. There are also demands to provide employment to the disabled; the integration of community-based rehabilitation programs into primary healthcare, screening, and follow-up programs in the field of blindness, deafness, mental retardation, and accident prevention; and prevent child abuse, addiction, delinquency, divorce, etc. Our research results allow the development of theoretical and practical approaches to assessing transversal and disciplinary competencies for social, economic, or environmental commitment (critical thinking, solving problems, social-emotional intelligence, ethical judgment, and others). 
In the WOI, competencies have not been addressed so far, and there is no specific trustee for it. All notable efforts in this area are limited to training needs assessment and performance appraisal, which do not have a particular process and framework due to the lack of relevance to a comprehensive model such as the competency framework. Therefore, it was necessary to develop an appropriate framework for identifying and determining the competencies required by employees in the Welfare Organization, despite all the complex conditions related to its specialized topics. The considered framework development aims to systematize the selection of employees of the WOI and take more effective measures toward their growth and development.

Therefore, the aims of the current study were as follows: (1) to develop a framework of the job competence of employees to examine the recruitment of employees in their specialized fields, and (2) to answer the question of whether the development of a framework of the job competence of employees in attracting and employing people or their appointment and promotion was effective in achieving the goals of the organization. Therefore, this study determined:

- The competency components of the employees of the welfare organization;

- The importance of each element of the competencies of the employees of the welfare organization;

- The logical pattern of the relationship between the core competency components.

\section{Research Background}

The history of the scientific view of the subject dates from less than a century. To identify the success factors of top American companies, Collins et al. [7] suggested that most leaders of successful organizations spent more time hiring and employing competent managers and employees than paying attention to the strategy and destination. In addition to technical capabilities and skills, they also paid attention to nontechnical competencies such as talent issues, behavior, and the personalities of individuals.

Competencies are associated with successful performance; therefore, they should be observed in observable behavior patterns positively and helpfully, to be defined in the form of behavioral patterns [8]. Hence, researchers classify competencies in different ways. Byham and Moyer [9] and Boyatzis [10] categorized competencies into individual, organizational, occupational, or role-related. Goudreau et al. [11] divided corporate and individual competencies. They attributed technical and functional competencies or duties to individual competencies.

Boam and Sparrow [12] defined competence as a set of behavioral patterns that a person must bring to a position in order to perform their actions and tasks competently. Their description of competence has simple but important features. First, employee competencies must be observable behaviors. At the same time, the operational variables-such as personality traits, values, motivations, and the like-that underlie behavior can be seen in behavioral patterns. Second, the description links patterns of behavior to job performance. The third, and probably the most implicit case, is that the concept of competence can include knowledge, skills, and abilities, as well as others beyond these characteristics; in particular, effective performance includes not only the ability to do work, but also the motivation or desire to do work.

Boyatzis [10] looked at competence as a distinguishing feature. Boyatz revealed the definition that underlined McClelland's work, and defined competency as characteristics that relate to superior or effective performance in the job in question. In other words, from the point of view of these experts, competencies are evidence that a person has characteristics for superior or effective performance.

Aaron et al. [13] tried to investigate the effect of the cultural competence of service industry employees on customers' experience. They stated that cultural awareness and skills significantly affected the service users, while cultural knowledge was not important. In addition, Berg et al. [14] determined team competence to be an enabling factor for achiev- 
ing agility and quality, optimizing manufacturing and logistical process, and increasing technical responsibility acceptance as an intrinsic attribute.

Faulks et al. [15] assessed the relationships between empowering leadership, innovative work behavior, organizational readiness for change, and sustainable economic performance. Using confirmatory factor analysis to estimate the maximum likelihood, they showed that there was a direct impact on sustainable economic performance produced by innovative work behavior and organizational readiness for learning. Moreover, they stated that leadership empowerment influenced innovative work behavior but did not affect sustainable economic performance.

Abdoulaye [16] investigated how selected human resource management practices, namely recruitment and selection; training and development; performance evaluation; remuneration; and promotion impacted employee retention through organizational commitment, trust, and inclusion. The author found that organizational commitment could act as a mediator between these HRM practices and employee retention.

Liang et al. [17] tried to introduce a validated process into management competency identification in Australia. They confirmed that the used four-stage process, including job description analysis, focus group discussions, and online surveys, could identify management competencies.

Geng et al. [18] constructed a competency framework for dentists in China using focus group interviews and in-depth personal interviews. They developed a dentist competency index with an expert consultation questionnaire. Using the Delphi method twice, the results of their study showed that the expert authority, enthusiasm, and coordination coefficients were high.

Perera et al. [19] identified the necessary competencies for ranking programs in higher education and developed a relevant framework. Their framework has two levels: macroand micro-competencies. Moreover, examples of knowledge, skills, and attitudes have been identified for each macro-competency. To design a competency framework for logistics executives in Egypt, among the various dimensions in the field, the relationship between competency and skills with logistics and education was addressed explicitly by El-Zarka [20]. From a business perspective, competencies related to issues such as globalization, outsourcing, new information technologies, total quality management, agility, rapid response, and environmental sustainability have been emphasized. Competencies related to learning organizations, skills requirements, and learning techniques have been mentioned.

In Slovakia, a competency framework for public sector employees and, particularly, managers in this sector was developed by Skorková [21]. Three main components were included in this framework, namely, professional knowledge, applied skills, and social maturity. The framework addresses the most important human resource management issues in the Slovak public sector: training and development programs, rewards, and the recruitment process.

Abdul [22] used a structured questionnaire to evaluate and analyze the views of experts in his study on the development of competency frameworks for employees working in human resources-related jobs in Malaysia. In his research, he identified three essential competencies under the headings behavioral, commercial, and technical. Moreover, he recognized the partial competencies involved in each of them. The most important professional competencies of stakeholders in public relations were addressed by Palea [23], who stated that people do not know much about the duties and competencies expected from employees in public relations. She distinguished between competencies and behaviors in her study, and concluded that, in most cases, competencies should ultimately lead to behaviors based on ethics and transparency. The researcher divided agents' competencies in public relations into three general categories: valuation, personality, and specialization. She also pointed out that competencies in public relations should not be limited to theoretical issues, but should be treated as a field and operational issue.

Fang et al. [24] categorized 18 competencies into 5 categories. The indicators of personality $(24 \%)$, planning $(21 \%)$, professional ability $(19 \%)$, management $(20 \%)$, and 
interpersonal ability $(13 \%)$ were essential at the first level to selecting managers. The two indicators of personality and planning were significant for middle managers. They claimed that most factors that determine managers' personalities are internal and difficult to observe, train, and develop. Therefore, to select managers, they suggested selecting individuals based on a complete and long-term observation and considering the planning ability that can be observed and expanded for this selection. At the second level, competencies, initiative, and attractiveness were the most important personality factors; organizing was the most important factor in the ability to plan; executive ability was the most critical factor in management; the factor of professional skills was the most important in professional ability; teamwork was the most important factor in interpersonal competence.

A model to define the competencies of hospital management was addressed by Pillay [25]. Using a questionnaire, he categorized 39 competencies into 5 categories. To prioritize these 5 skill categories, he used a sample of 404 managers from both the public and private sectors. The results showed that, in both sectors, managers prioritized skills in the same way: "people management skill" and "self-management skills" were the most important skills, followed by "hard management skills" and "strategic skills".

Stelf et al. [26] proposed a framework to show the competencies needed by managers in the health system. This framework enumerates five categories of competencies that all managers in the health industry should have. The first category is relationship and communication management, including relationship management, communication skills, and facilitation and negotiation. The second category is leadership skills, including leadership behavior and skills, organizational culture and atmosphere, communication perspective, and change management. The third category is professionalism, which includes individual and corporate accountability, professional development and long-term training, and helping the community and the health profession. The fourth category is knowledge of the health environment, including health systems and organizations, health personnel, patients' perspectives, and society and the environment. The fifth category of skills is knowledge and work skills that include the following subcategories: general management, financial management, human resource management, organizational development and dynamics, strategic planning and marketing, information management, risk management, and quality improvement.

Shewchuk et al. [27] designed a framework using the opinions of hospital managers to list the problems of hospitals, categorize them into five categories, and then collect the competencies needed to solve these problems according to their statements. These competencies were categorized into five types, from the most important to the least important: "focus on patient or client", "health operations management", "economic and financial issues", "ethical, legal, and political issues", and "physician-staff relations". A sample of 72 experts was then asked to prioritize these competencies. But unlike the initial chart designed by the panel of experts, this time, "physician-staff relations" was considered the most important skill, followed by "health operations management", "ethical, legal, and political issues", "focus on patient or client", and "economic and financial issues".

MacKinnon et al. [28] categorized 31 competencies required by hospital managers into 9 categories, in order to introduce a framework for management competencies for Canadian health executives. A sample of 485 hospital managers was then asked to prioritize these competencies. Participants agreed on 31 competencies. Among the 9 main groups, "competence", "communication", and "perceptual skills" had the highest mean score. The "long-term learning" group was recognized as the least important group. The 5 competencies that mattered most among the 31 competencies were "teambuilding", "listening", "flexibility in effectively managing change", "verbal communication", and "commitment to the customer", all subdivisions of leadership and communication. The five competencies that were prioritized as the least essential competencies included the following: "a commitment to health service management position", "management of valuable resources", "promotion of agreement on standards", "training and mentoring for employees", and "monitoring environmental processes to predict their impact on the organization". 
Reviewing the definitions and background provided, it can be concluded that the main components of competencies that are effective in successful professional activities are: knowledge, abilities, skills, personality and moral characteristics, attitudes and insights, and public and professional credentials. These are essential to the successful performance of professional activities and effectiveness in the performance of the individual and the organization.

\section{Methodology}

This research was a developmental and descriptive-exploratory study in terms of its data collection. The project was implemented in seven stages (Figure 1):

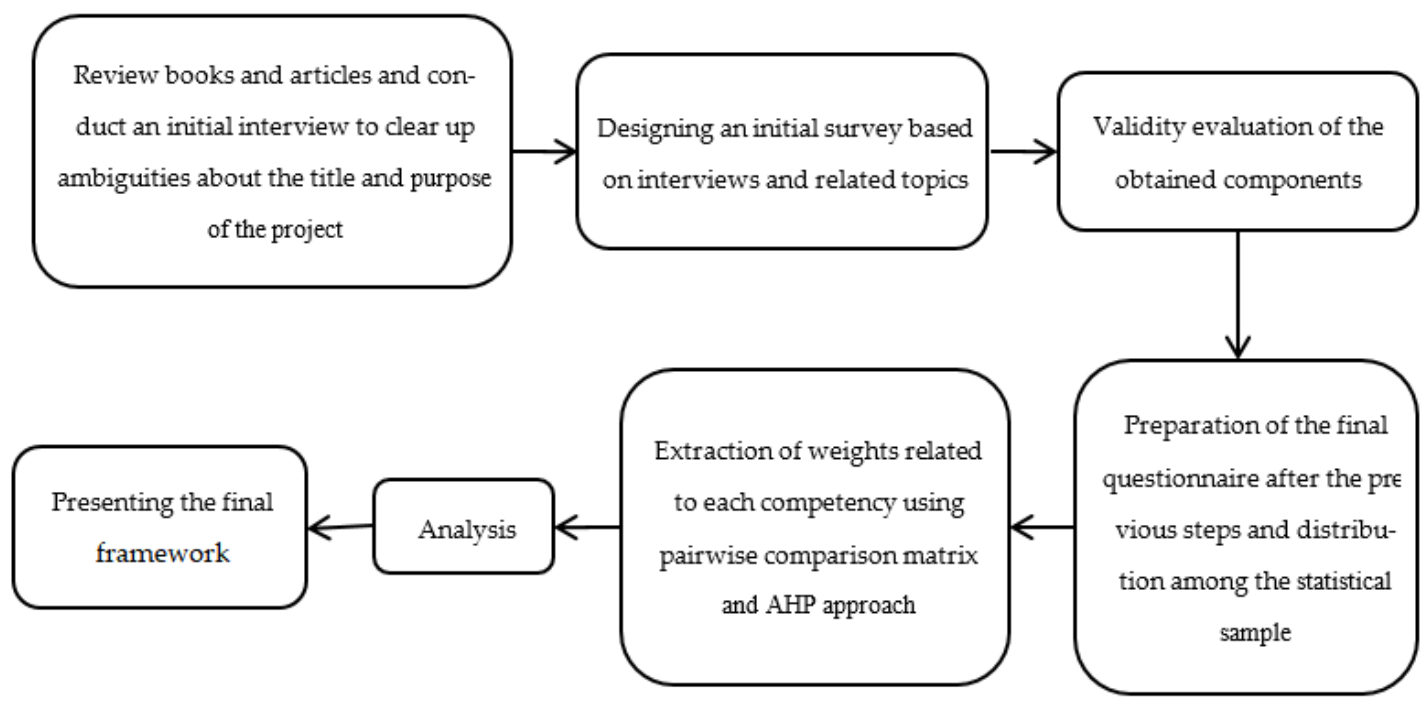

Figure 1. Method of conducting research and achieving the final framework.

In the first step, to identify the primary and secondary components of the appropriate competencies of this research, the existing frameworks were examined through library studies. Accordingly, the components of common and non-common competence were identified, and according to the special requirements of environments such as the Welfare Organization, new components were considered. These components were first provided to at least five senior managers and professors in the field of welfare and human resource management, and their opinions on the proposed cases were received.

In the second step, the identified components were logically analyzed, and based on the reciprocal and interactive relationships between them, the initial framework of the competencies of the employees of the Welfare Organization was adjusted and proposed. Accordingly, a general list of competencies and their definitions was developed to prevent bias errors.

In the third step, the opinions of the sample members were collected through a crosssectional self-administered questionnaire regarding the characteristics of the proposed components.

For categorization in the fourth step, the collected data were analyzed; then, knowledge, skills, and essential attitudes related to each other were categorized into general competencies. An explanatory statement was provided for each of the competencies listed in this way.

In the fifth step, for determining the significance of each of the primary and secondary competencies, the opinions of experts based on the approach of the hierarchical analysis process (AHP) [29] were used; then, the consensus of different groups in this field was examined and analyzed. In assessing the degree of agreement and consensus, the data of Expert Choice software were used to calculate the agreement coefficient accordingly.

During this step, the indicators were drawn as a tree, and by designing three questionnaires, different sectors were asked to express the importance of each indicator in relation 
to the others. In this method, according to the results of the knowledge and experience of experts and the use of the available information, weights were assigned to each of the factors. In this way, first, the weights were calculated separately through the expert knowledge and data; then, the desired weight was determined by comparing the obtained values. As a result, the probability of making a mistake was reduced and the weights would be closer to reality. In these comparisons, decision-makers used oral judgment. This comparison was such that, if element $i$ was compared with element $j$, the importance of one over the other would be one of the states in Table 1. The next step was to convert verbal preferences to numerical values (Appendix A) according to Table 1.

Table 1. Assignation of numbers to pairwise comparison preferences.

\begin{tabular}{cc}
\hline Preferences & Value \\
\hline Completely preferred or completely more important & 9 \\
Preference or importance is very strong & 7 \\
Strong preference or importance & 5 \\
The less preferred or the less important & 3 \\
The preference or importance is the same & 1 \\
Preferences between the above distances & $2,4,6,8$ \\
\hline
\end{tabular}

These questionnaires were designed to assess the identification factors. The criteria extracted from the theoretical foundations and holding meetings with experts through interviewing and evaluating it allowed us to examine the competencies of the specialized welfare professional fields. Thus, a closed-ended questionnaire using a five-point Likert scale (very high, high, medium, low, and very low) was provided to the statistical sample of the research, and it was evaluated and ranked through statistical tests. After categorizing the competencies and finalizing them using experts' opinions, the AHP approach was used to weight the competencies to achieve the research objectives and test the questions.

\subsection{Research Population}

The research community consisted of all employees working in the specialized fields of the Welfare Organization, 566 individuals. Since the number of trusted experts was not significant to comment on the list of competencies and to make a pairwise comparison, all of them were used to complete the questionnaires. The situation of the specialized employees of the Welfare Organization in Mazandaran province is shown in Table 2.

Table 2. Status of specialized employees of the Welfare Organization in Mazandaran province.

\begin{tabular}{ccc}
\hline Category & Occupation/Department & Number \\
\hline & Planning expert & 1 \\
& Legal expert & 10 \\
Thematic statistics expert & 2 \\
& Social worker & 22 \\
& Employment and placement expert & 21 \\
& Assistance of a welfare expert & 8 \\
& Welfare expert & 321 \\
& Total & 385 \\
\hline
\end{tabular}


Table 2. Cont.

\begin{tabular}{ccc}
\hline Category & Occupation/Department & Number \\
\hline & Educational instructor & 1 \\
Instructor for the education of the & disabled & 1 \\
Educational and cultural & Childcare & 40 \\
& Sports expert & 2 \\
& Cultural affairs expert & 1 \\
Total & 3 \\
& Practical nurse & 48 \\
\hline Health and treatment & Nurse & 4 \\
& Rehabilitation expert & 8 \\
& Family health expert & 62 \\
Mental health experts & 1 \\
& Physician & 31 \\
& Nutrition and diets expert & 8 \\
& Disability social workers & 1 \\
& Total & 18 \\
\hline Total number of specialized welfare employees & 131 \\
\hline
\end{tabular}

\subsection{Description of Competencies}

The competencies' descriptions for the spheres of "healthcare", "social" and "educational and cultural" are listed in Table 3. These descriptions were also used in the questionaries distributed among the respondents.

Table 3. Description of the competencies in the healthcare, social and educational, and cultural spheres.

\begin{tabular}{|c|c|}
\hline Title & Description \\
\hline $\begin{array}{l}\text { Effective communication with } \\
\text { others }\end{array}$ & $\begin{array}{l}\text { Establishes appropriate communication with clients in order to identify their needs and } \\
\text { expectations, describe the necessary services and actions, and reach an agreement on how to } \\
\text { follow up. }\end{array}$ \\
\hline Compiling reports & $\begin{array}{l}\text { Writes and compiles concise and clear information, evidence, causes of problems and } \\
\text { events, and their logical and sequential analysis to reach the appropriate solution }\end{array}$ \\
\hline $\begin{array}{l}\text { Decision making and problem } \\
\text { solving }\end{array}$ & $\begin{array}{l}\text { Gathers and analyzes information about a topic, searches and creates solutions, compares } \\
\text { different solutions, and chooses the best way to deal with a problem. }\end{array}$ \\
\hline $\begin{array}{l}\text { Assessment and monitoring of } \\
\text { harms }\end{array}$ & Determines the status of health injuries based on defined indicators and criteria. \\
\hline Planning healthcare interventions & $\begin{array}{l}\text { Establishes a process consisting of specific and interconnected steps to produce a coherent } \\
\text { output within a coordinated military framework of decisions to deal with health damage. }\end{array}$ \\
\hline $\begin{array}{l}\text { Directing the implementation of } \\
\text { healthcare interventions }\end{array}$ & $\begin{array}{l}\text { Plays the role of leadership in the implementation of health intervention programs with the } \\
\text { optimal use of efficient people and various available resources. }\end{array}$ \\
\hline $\begin{array}{l}\text { Evaluation of healthcare } \\
\text { interventions }\end{array}$ & $\begin{array}{l}\text { Investigates the impact of health intervention programs at different levels and identifies the } \\
\text { factors of success or failure in achieving goals. }\end{array}$ \\
\hline Social harm assessment & Determines the status of health injuries based on defined indicators and criteria. \\
\hline $\begin{array}{l}\text { Planning welfare and social } \\
\text { interventions }\end{array}$ & $\begin{array}{l}\text { Establishes a process consisting of specific and interconnected steps to produce a coherent } \\
\text { output within a coordinated military framework of decisions to deal with health damage. }\end{array}$ \\
\hline $\begin{array}{l}\text { Directing welfare and social } \\
\text { interventions }\end{array}$ & $\begin{array}{c}\text { Plays the role of leadership in the implementation of health intervention programs with the } \\
\text { optimal use of efficient people and various available resources. }\end{array}$ \\
\hline
\end{tabular}


Table 3. Cont.

\begin{tabular}{|c|c|}
\hline Title & Description \\
\hline $\begin{array}{l}\text { Evaluation of welfare and social } \\
\text { interventions }\end{array}$ & $\begin{array}{l}\text { Investigates the impact of health intervention programs at different levels and identifies the } \\
\text { factors of success or failure in achieving goals. }\end{array}$ \\
\hline $\begin{array}{l}\text { Educational and cultural needs } \\
\text { assessment }\end{array}$ & $\begin{array}{l}\text { Assesses the status of the audience and the organization and identifies educational and } \\
\text { cultural needs based on defined indicators and criteria. }\end{array}$ \\
\hline $\begin{array}{l}\text { Planning educational and cultural } \\
\text { interventions }\end{array}$ & $\begin{array}{l}\text { Creates a process consisting of specific and interconnected steps to produce a coherent } \\
\text { output within a coordinated military framework of decisions in order to empower and meet } \\
\text { educational and cultural needs. }\end{array}$ \\
\hline $\begin{array}{l}\text { Directing educational and cultural } \\
\text { interventions }\end{array}$ & $\begin{array}{l}\text { Plays the role of leadership in the implementation of educational and cultural intervention } \\
\text { programs with the optimal use of efficient people and various available resources. }\end{array}$ \\
\hline $\begin{array}{l}\text { Evaluation of educational and } \\
\text { cultural interventions }\end{array}$ & $\begin{array}{c}\text { Investigates the impact of educational and cultural intervention programs at different levels } \\
\text { and identifies the factors of success or failure in achieving goals. }\end{array}$ \\
\hline
\end{tabular}

\subsection{Data Collection}

In this research, two approaches, library studies and field studies, were used to collect the data. In-depth and exploratory individual interviews were used in the qualitative part of this research. First, before the interview, managers were provided with information about the competencies required of employees in specialized welfare careers; then, the interviewees were asked to provide factors that could establish the basis for designing a framework for the characteristics and competencies of employees. Following the interview process, the researcher analyzed the data to complete incomplete cases by receiving new information from the new participants. The interviews were conducted until factors were repeated [30-32]. After reviewing and confirming the questionnaire, which was designed according to the presented hypotheses, it was sent to the subject experts to check the face and content validity. After one month, the answers were collected and analyzed.

\subsection{Content Validity}

The first step in determining the validity is always to check the content validity. Content validity depends on the logical analysis of the content of a survey, and its determination is based on subjective and individual judgment. In this method, survey questions are given to specialists or some of the respondents and they are asked to determine whether the questions measure the desired trait or not and whether the questions cover the entire survey content. Using Equations (1) and (2), the content validity ratio (CVR)and content validity index (CVI) can be calculated as follows.

$$
\begin{gathered}
C V R=\frac{\text { Number of panel indicating "necessary" }-\frac{\text { Total number of panel }}{2}}{\frac{\text { Total number of panel }}{2}} \\
C V I=\frac{\text { Number of panel rating the item } 3 \text { or } 4}{\text { Total number of panel }}
\end{gathered}
$$

Panel members are asked to categorize each question based on a three-point Likert scale as "item is necessary", "item is useful but not necessary", or "item is not necessary". According to Lawshe Table [33], items for which the calculated CVR is less than the determined value according to Lawshe Table, should be eliminated.

For the present study, Waltz and Bausell's method [34] was used to check the content validity index. Experts defined each item in terms of "relevancy", "clarity", and "simplicity", based on a four-point Likert scale. Experts rated the relevancy of each item as 1 "irrelevant", 2 "relatively relevant", 3 "relevant", or 4 "completely relevant". The simplicity of the item also ranged from 1 "not simple", 2 "relatively simple", 3 "simple", to 4 "simple relevant". The clarity of each item was classed as 1 "not clear", 2 "relatively clear", 3 "clear", or 4 "clearly relevant". 
Based on the evaluation indicators and defined standards, the numbers of suitable competencies for healthcare, social affairs, and educational and cultural spheres were determined to be 20,11, and 33, respectively.

\section{Results}

In this research, in several stages, it was necessary to identify, modify, categorize, and prioritize employees' competencies. Based on a survey conducted through interviews with experts of the organization and reviews of missions, job duties, and library documents, including previous studies and research, 108 competencies were identified for the 3 job categories of welfare employees - that is, "social affairs", "educational and cultural", and "healthcare". All items were used for each category to avoid bias and the possibility of further differentiation between competencies from the respondents' point of view. Questionnaires were provided to employees with at least a bachelor's degree, and the answers were analyzed and evaluated. However, some cases referred to individuals with an associate degree who had a good experience. In general, 51 answers were considered appropriate out of the answers provided by 70 experts of the organization, and the rest were rejected. The demographic characteristics of the respondents are as follows.

According to Table 4, out of 51 correct answers received, 37 (73\%) were female and 14 $(27 \%)$ were male. Moreover, 18 (40\%) of respondents had under 10 years of work experience, $3(7 \%)$ had 10 to 15 years, $9(20 \%)$ had 15-20 years, and $15(33 \%)$ had over 20 years of work experience. In terms of educational degree, $5(10 \%)$ respondents held an associate degree, 32 (63\%) held a bachelor's degree, 12 (24\%) held a master's degree, and $2(4 \%)$ held a doctorate. Table 2 also shows that out of the 51 correct answers received, 25 cases $(50 \%)$ were related to the social affairs sphere, 17 cases $(33 \%)$ were related to the healthcare sphere, and 9 cases (17\%) were related to the educational and cultural sphere.

Table 4. Demographic characteristics of the respondents.

\begin{tabular}{lcc}
\hline & Number of Respondents & $\%$ \\
\hline Gender & 37 & 73 \\
Male & 14 & 27 \\
Female & 18 & \\
Working experience & 3 & 40 \\
$<10$ & 9 & 20 \\
$10-15$ & 15 & 33 \\
$15-20$ & & \\
$>20$ & 5 & 10 \\
Educational degree & 32 & 63 \\
Associate & 12 & 24 \\
Bachelor & 2 & 4 \\
Master & & \\
Doctorate & 25 & 50 \\
Response rate & 17 & 33 \\
Social affairs & 9 & 17 \\
Health and therapeutic & & \\
Educational and cultural & & \\
\hline
\end{tabular}

\subsection{Data Analysis}

It was necessary first to disambiguate the competencies of each job sphere and then combine and categorize them. Furthermore, they were described based on the assigned duties and responsibilities, and the weights of each of them were determined. In this regard, a pairwise comparison matrix related to the three categories of "healthcare", "social affairs", and "educational and cultural" was formed, and the weights of competencies were determined, which are shown as significant in Table 5. To calculate the weights of each index from the pairwise comparison method, the AHP approach was used. The matrices are presented in Appendix A. In completing the pairwise comparison matrix, the opinions 
of at least ten experts of the Welfare Organization, including senior managers, professors in the field of welfare, and human resource management, were used. To reach the final matrix, the geometric mean of each element was extracted.

Table 5. Categorization of competencies related to the sphere of healthcare.

\begin{tabular}{|c|c|c|c|c|}
\hline & General Title & Significant & Competencies & CVR \\
\hline \multirow{6}{*}{1} & \multirow{6}{*}{ Effective communication with others } & \multirow{6}{*}{0.15} & Listening & 0.76 \\
\hline & & & Stress management and control & 0.76 \\
\hline & & & Communication with others & 0.76 \\
\hline & & & Psychological counseling & 0.88 \\
\hline & & & Sympathy & 0.65 \\
\hline & & & Communicating with high-risk people & 0.53 \\
\hline \multirow{2}{*}{2} & \multirow{2}{*}{ Compiling reports } & \multirow{2}{*}{0.22} & Reporting & 0.53 \\
\hline & & & $\begin{array}{l}\text { Writing administrative } \\
\text { correspondence }\end{array}$ & 0.65 \\
\hline \multirow{3}{*}{3} & \multirow{3}{*}{ Decision making and problem solving } & \multirow{3}{*}{0.07} & Decision making & 0.88 \\
\hline & & & Problem solving & 0.65 \\
\hline & & & $\begin{array}{l}\text { Assessing the rehabilitation of the } \\
\text { disabled }\end{array}$ & 0.88 \\
\hline \multirow{3}{*}{4} & \multirow{3}{*}{ Assessment and monitoring of harms } & \multirow{3}{*}{0.05} & Evaluation of welfare services & 0.53 \\
\hline & & & Identify vulnerable people & 0.65 \\
\hline & & & Classification of disabilities & 0.65 \\
\hline 5 & Planning healthcare interventions & 0.04 & Allocation of facilities and resources & 0.53 \\
\hline \multirow{3}{*}{6} & \multirow{3}{*}{$\begin{array}{l}\text { Directing the implementation of } \\
\text { healthcare interventions }\end{array}$} & \multirow{3}{*}{0.24} & Description of services & 0.53 \\
\hline & & & Description of types of insurance & 0.53 \\
\hline & & & $\begin{array}{l}\text { Description of rehabilitation } \\
\text { interventions }\end{array}$ & 0.88 \\
\hline 7 & Evaluation of healthcare interventions & 0.23 & Performance evaluation & 0.88 \\
\hline
\end{tabular}

The titles of competencies and their general titles related to the healthcare sphere are shown in Table 4. Accordingly, the CVI of each item is included for this sphere, based on the opinions of 17 experts. The minimum acceptable value for 17 experts according to Lawshe's table is 0.529 [35].

According to Table A1, the incompatibility coefficient was calculated to be 0.03 . Therefore, the competencies of "planning healthcare interventions" and "assessing and monitoring of harms" could be omitted because they were insignificant. By removing these two competencies and normalizing the weights again, the weights of the competencies of "effective communication with others", "compiling reports", "decision-making and problem-solving", "directing the implementation of healthcare interventions", and "evaluation of healthcare interventions" became $0.16,0.24,0.09,0.26$, and 0.25 , respectively. Therefore, "directing the implementation of healthcare interventions" was the most important competency, and "decision-making and problem-solving" was the least important one. In other words, healthcare workers were expected to have expertise in guiding and implementing healthcare programs.

The titles of the competencies and their general titles related to the sphere of social affairs are shown in Table 6. Accordingly, the CVI of each item was included for this sphere based on the opinions of 17 experts. The minimum acceptable value for 20 experts according to Lawshe's table is 0.500 [35]. 
Table 6. Categorization of competencies related to the social affairs sphere.

\begin{tabular}{|c|c|c|c|c|}
\hline & General Title & Significant & Competencies & CVR \\
\hline 1 & Effective communication with others & 0.09 & $\begin{array}{c}\text { Listening } \\
\text { Interviewing } \\
\text { Attract the support of others } \\
\text { Adjust body language }\end{array}$ & $\begin{array}{c}0.92 \\
0.69 \\
1 \\
0.50\end{array}$ \\
\hline 2 & Compiling reports & 0.23 & Reporting & 0.88 \\
\hline 3 & Decision making and problem solving & 0.03 & Problem solving & 0.88 \\
\hline 4 & Social harm assessment & 0.21 & Classification of social harms & 1 \\
\hline 5 & Planning welfare and social interventions & 0.07 & Evaluation of welfare services & 0.54 \\
\hline 6 & Directing welfare and social interventions & 0.10 & Explaining the delivery of services & 0.44 \\
\hline 7 & $\begin{array}{c}\text { Evaluation of welfare and social } \\
\text { interventions }\end{array}$ & 0.27 & Measuring social consequences & 0.56 \\
\hline
\end{tabular}

According to Table A2, the incompatibility coefficient was calculated to be 0.03 . Therefore, the competency of "decision-making and problem-solving" was omitted as they were insignificant. By removing these competencies and normalizing the weights again, the weights of the competencies of "effective communication with others", "compiling reports", "social harm assessment", "planning welfare and social interventions", "directing welfare and social interventions", and "evaluation of welfare and social interventions" became $0.09,0.24,0.22,0.07,0.10$, and 0.28 , respectively. Therefore, "evaluation of welfare and social interventions" was the most important competency, and "planning welfare and social interventions" was the least important. In other words, healthcare workers were expected to have a high level of expertise in evaluating the effectiveness of implemented welfare and social programs.

The titles of competencies and their general titles related to the educational and cultural sphere are shown in Table 7. Accordingly, the CVI of each item is included for this sphere based on the opinions of 17 experts. Minimum acceptable value for 9 experts according to Lawshe's table is 0.778 [35].

Table 7. Categorization of competencies related to the educational and cultural sphere.

\begin{tabular}{|c|c|c|c|c|}
\hline & General Title & Significant & Competencies & CVR \\
\hline \multirow{4}{*}{1} & \multirow{4}{*}{$\begin{array}{l}\text { Effective communication } \\
\text { with others }\end{array}$} & \multirow{4}{*}{0.03} & Motivating & 1 \\
\hline & & & Oral communication & 1 \\
\hline & & & Negotiation & 1 \\
\hline & & & Adjust body language & 0.78 \\
\hline \multirow{3}{*}{2} & \multirow{3}{*}{ Compiling reports } & \multirow{3}{*}{0.05} & Reporting & 1 \\
\hline & & & Writing administrative & 0.78 \\
\hline & & & $\begin{array}{l}\text { correspondence } \\
\text { Documenting the experiences }\end{array}$ & 1 \\
\hline \multirow{5}{*}{3} & \multirow{5}{*}{$\begin{array}{l}\text { Decision making and } \\
\text { problem solving }\end{array}$} & \multirow{5}{*}{0.05} & Time Management & 1 \\
\hline & & & Decision making & 1 \\
\hline & & & Problem solving & 1 \\
\hline & & & Facilitation & 1 \\
\hline & & & Proposal & 1 \\
\hline \multirow{7}{*}{4} & \multirow{7}{*}{$\begin{array}{l}\text { Educational and cultural } \\
\text { needs assessment }\end{array}$} & \multirow{7}{*}{0.15} & Performance evaluation & 1 \\
\hline & & & Following a standard & 1 \\
\hline & & & Monitoring environmental trends & 1 \\
\hline & & & $\begin{array}{l}\text { affectıng the organızation } \\
\text { Quality improvement }\end{array}$ & 1 \\
\hline & & & Cultural pathology & 1 \\
\hline & & & Social pathology & 1 \\
\hline & & & Pathology of individual behavior & 1 \\
\hline
\end{tabular}


Table 7. Cont.

\begin{tabular}{|c|c|c|c|c|}
\hline & General Title & Significant & Competencies & CVR \\
\hline 5 & $\begin{array}{l}\text { Planning educational and } \\
\text { cultural interventions }\end{array}$ & 0.25 & $\begin{array}{c}\text { Targeting } \\
\text { Indexing } \\
\text { Planning } \\
\text { Receive financial resources } \\
\text { Employee empowerment } \\
\text { Discipline } \\
\text { Cultural planning } \\
\text { Action research design }\end{array}$ & $\begin{array}{c}1 \\
1 \\
1 \\
1 \\
1 \\
1 \\
1 \\
0.78\end{array}$ \\
\hline 6 & $\begin{array}{l}\text { Directing educational and } \\
\text { cultural interventions }\end{array}$ & 0.15 & $\begin{array}{c}\text { Flexibility in change management } \\
\text { Valuable resource management } \\
\text { Operational capability }\end{array}$ & $\begin{array}{l}1 \\
1 \\
1\end{array}$ \\
\hline 7 & $\begin{array}{l}\text { Evaluation of educational } \\
\text { and cultural interventions }\end{array}$ & 0.32 & $\begin{array}{c}\text { Measuring social consequences } \\
\text { Assessing life skills } \\
\text { Cost-benefit analysis }\end{array}$ & $\begin{array}{c}0.78 \\
1 \\
1\end{array}$ \\
\hline
\end{tabular}

According to Table A3, the incompatibility coefficient was calculated to be 0.02 . Therefore, the competencies of "effective communication with others", "compiling reports", and "decision-making and problem-solving" were insignificant and were omitted. By removing these three competencies and normalizing the weights again, the weights of competencies of "educational and cultural needs assessment", "planning educational and cultural interventions", "directing educational and cultural interventions", and "evaluation of educational and cultural interventions" became $0.19,0.28,0.17$, and 0.36 , respectively. Therefore, "evaluation of educational and cultural interventions" was the most important competency, and "directing educational and cultural interventions" was the least important. In other words, it was expected that the educational and cultural field employees would have a high level of expertise in evaluating the effectiveness of the implemented educational and cultural programs.

\subsection{Proposed Relevance Frameworks}

The issue which is important in the final competencies extracted is that their significance in the form of missions, job descriptions, and assigned responsibilities should be related to each of the job categories. In other words, the managers of these jobs should have used competencies, and if an employee had them, the desirability of their job behavior and performance should have been guaranteed. Therefore, it was necessary to examine whether or not such conditions were met for the competencies extracted in this research.

Employees in the healthcare sphere deal with affairs such as nursing, rehabilitation, family health, mental health, practicing, nutrition, and care for the disabled. In other words, employees in this sphere should play a role in implementing programs and measures in the field of healthcare. It is important, then, to evaluate the impacts of the actions taken. They need to write reports, communicate with others, make decisions and solve problems. As shown in the results of this study, they do not play a significant role in planning healthcare interventions, and the top managers communicated such cases to them. However, it is essential to run the programs correctly, solve problems and failures during the implementation, receive feedback, etc.

Communicating with others seems to go back to the conditions under which actions are taken, and even decision-making and problem-solving go back to this issue. Employees in this department should communicate appropriately with people under treatment or care. If there is a problem during work, they should solve it and make the necessary decisions. Analyzing the results of actions and providing feedback to improve and develop the programs are other parts of decision-making and problem-solving. With such an understanding, and by the exchange of views made with the organization's experts, the proposed framework for the employees' competencies of this sphere can be shown in Figure 2. 


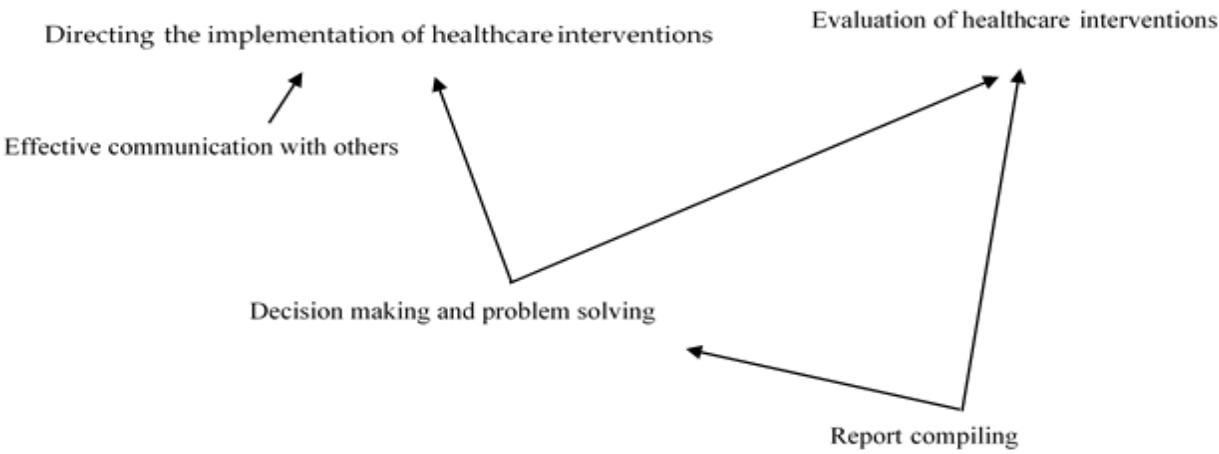

Figure 2. Proposed relevance framework for healthcare competencies.

Employees of the social work profession sphere deal with affairs such as legal, social work, employment and recruitment, social harm care, addiction, counseling, and guidance. In other words, employees in this field should, above all, play a role in evaluating the effectiveness of programs and actions developed in the field of social affairs. Thus, preparing appropriate reports is essential. They should be able to identify and assess social harms in their area of responsibility and then play a role in planning and implementing programs. Moreover, they seem to play a role in macrolevel comprehensive plans and play a lesser role in those plans' development. Thus, it makes sense to monitor and evaluate the impacts and to prepare and submit relevant reports. Employees in this field should be able to play an appropriate role in identifying social harms to assess needs and plan necessary actions and interventions. Proper communication with the audience and potential and actual beneficiaries of the program is essential in such cases. With such an understanding and by the exchange of views made with the organization's experts, the proposed framework for the competencies of the employees of this field can be shown in Figure 3.

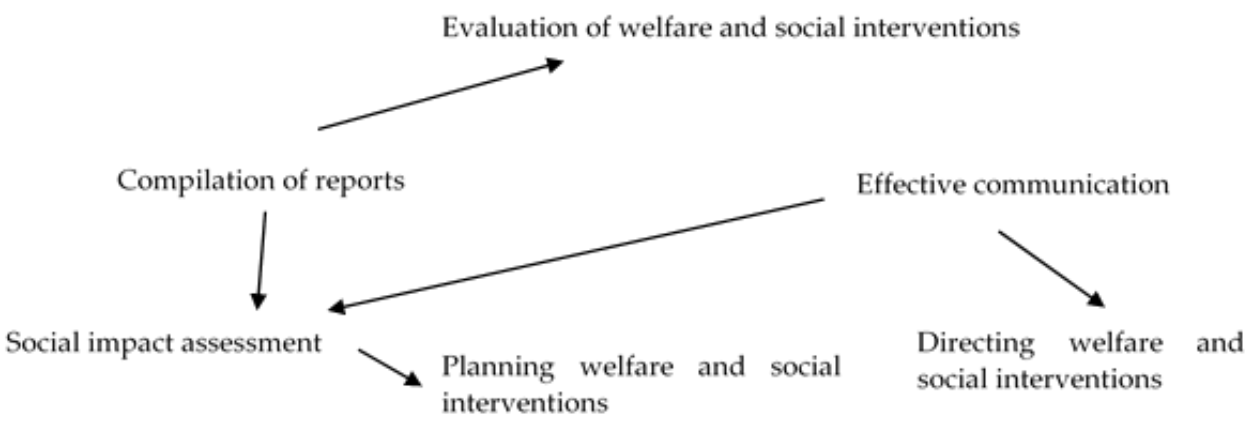

Figure 3. Proposed relevance framework for social affairs competencies.

Employees of the educational and cultural sphere deal with affairs such as women and families, the elderly, children and adolescents, the disabled, addiction, social harms, technical and vocational education, training, sports, and culture. In other words, employees in this field should play a role above all in evaluating the effectiveness of programs and actions developed in their work area. Thus, developing appropriate educational and cultural programs is crucial. They should also identify and analyze educational and cultural needs and play a role in directing the implementation of programs. The rationale followed by work in this area can be understood as follows: employees follow a pattern of educational and cultural needs assessment, educational and cultural planning, implementation of programs, and evaluating the effects of programs. Schematically, the pattern is shown in Figure 4. Educational needs assessment and training effectiveness evaluation are interrelated, as seen in the framework for educational and cultural competencies. 


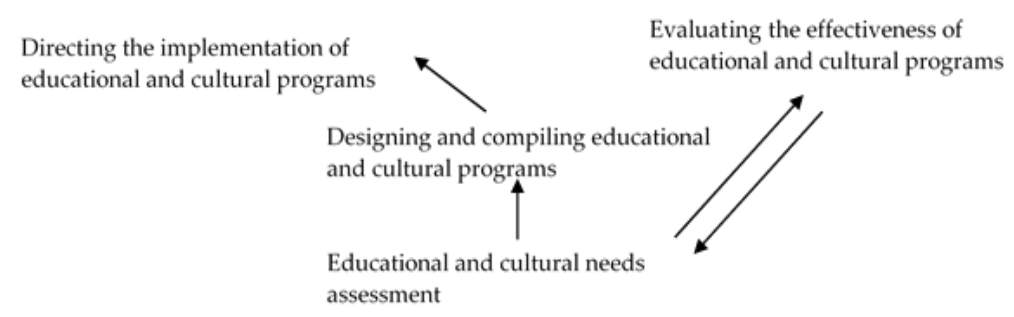

Figure 4. Proposed relevance framework for educational and cultural competencies.

\section{Discussion}

We discuss the following: first, setting the identified competencies in the form of a framework for each of the job categories; second, presenting suggestions for how to use the research results. The extracted competency patterns show the process of doing things by employees in different disciplines and indicate what competencies are needed to perform tasks and pursue responsibilities. The obtained patterns are closely related to the framework presented by Shewchuk et al. [23] in terms of the quantity (number), difference in importance, and relationship with the executive process. The significance of importance can be interpreted as having at least three competencies in each framework that differ by more than 5\%. The results show that the respondents were concerned with the process and planning in doing business despite the importance of a lot of knowledge, skills, and attitudes in the usual job analysis methods. Some organizations use a combination of two approaches ("one size fits all" and "multiple patterns") as an intermediate approach to developing competency frameworks [36].

It is important to notice the significance of the final extracted competencies, in the form of missions, job descriptions, and assigned responsibilities related to each job category. In other words, competencies should be used by those in charge of these jobs, and if people have them, the desirability of their job behavior and performance should be guaranteed. Therefore, it was necessary to examine whether or not such conditions were met for the competencies extracted in this research. The issue of the digital transfer impact on competency frameworks could be a topic for future research [37,38], as well as both integrated approaches to talent management in the organization [39] and educational innovation studied in work [40].

In this study, we investigated the Welfare Organization of Iran (WOI), since it is the main government institution to organize the vulnerable spectrum of society. The WOI is responsible for vital duties in several matters. On the one hand, the responsibility for providing welfare for many disabled people in society has been assigned to this organization. On the other hand, the task of arranging the situation of many deprived women and children in the society is within the responsibilities of the WOI. Therefore, human resources have a special place in this organization. According to the organization's perspective, employees' proper and appropriate employment and appointment in organizing and reaching the target community is very important.

In the WOI, which has a variety of jobs, there are two approaches to developing competency frameworks: the "one-size-fits-all" approach and the "multiple patterns" approach. In the one-size-fits-all approach, a set of overall competencies for all jobs in the organization is defined and exploited. A collection of general competencies, including 25-35 competencies, is identified for all occupations in the multiple patterns approach. Then, decisions are made by forming focus groups as to which competencies are appropriate for a particular job. This process is repeated to determine the competencies required for all positions.

In this regard, focusing on the role and importance of employees in today's organizations and the most critical challenges that have occupied them, it can be said that many expectations are raised about them. Today's organizations, including the WOI, face different expectations from government officials every day, and understanding and pursuing the fulfillment of these expectations is of great importance. 
The main contribution of this study is as follows: this issue has not been addressed in the Welfare Organization of Iran, and there is no specific trustee responsible for it. All significant efforts in this area are limited to training needs assessment and performance appraisal, which do not have a particular process and framework due to the lack of relevance to a comprehensive framework, such as a competency framework. Therefore, despite all the complex conditions related to its specialized topics, it is necessary to develop an appropriate framework for identifying and determining the required competencies of employees in WOI, so that more effective measures can be taken in terms of their growth and development, while systematizing the selection of employees of the WOI.

\section{Conclusions}

Examining all the extracted frameworks, it can be concluded that, in all the studied job categories, the ability to play an appropriate role in the implementation of programs and operational measures, as well as evaluating the effectiveness of these programs and providing relevant feedback, was of particular importance. This indicates that, to a large extent, the WOI's plans and operational measures had a particular theme and content. Employees were expected to be seriously involved in implementing programs or their own improvement. Furthermore, from this perspective, it can be said that the educational and cultural environment had more dynamism and flexibility than other cases. It was judged necessary for the employees in this field to have the required capabilities in the areas of needs assessment and planning.

Determining the priority of competencies also indicates that, at the provincial level, the expectations of individuals regarding different competencies were not the same. Of course, the results cannot be extended to the whole country or the WOI as a whole. For example, as the titles of the extracted competencies show, the expectations revolved around the implementation issues and the guidance of the communicated programs, and then, the evaluation at the local level was considered. At the same time, the study of the fields and contexts of program development and program implementation, and the adoption of specific strategies in this regard, could be partially designed and explained. This means that comprehensive and macroplanning was not considered in terms of received perspectives and the extracted frameworks. It can be inferred that, at this level of organizational structure, and in an area such as the province, there was no expectation that employees would act locally to adopt a strategy and develop, implement, and finally evaluate plans. However, according to the existing local issues, cultural and educational affairs could provide an executive solution and pursue it to the end as an exception.

It seems that, in the field of missions related to health and social affairs, operational strategies and solutions were extracted at the macro-level of the country and communicated to the provinces for implementation. Hence, these two occupations' competencies related to macroplanning matters have not been considered. The results of the research allow extending theoretical and practical approaches to framework transversal and disciplinary competencies for a social, economic, or environmental commitment based on the sustainability concept (critical thinking skills, problem-solving, social-emotional, ethical, and others).

\subsection{Limitation}

One of the most essential uncontrollable limitations in the present study was the lack of capable experts in cooperation with researchers-which, of course, was related to the objectives of the research. In other words, the questionnaires were completed with great difficulty, and, unfortunately, there was no good motivation in this regard. Given that, as is evident in the framework of competencies, welfare jobs have a research and analytical nature, employees must receive the training required in this regard. This is probably due to the unfamiliarity and inexperience of experts concerning the method used in the present study. 
Another limitation beyond the researchers' control was the current situation governing the Welfare Organization of Iran and the principles and methods used in it to carry out the assigned missions and achieve the relevant goals. Job duties arise from tasks, and the knowledge, skills, and attitudes required to do things, followed by job competencies, refer to the tools and methods used to perform the tasks. Naturally, if the methods change for various reasons, and other tools and technologies are used to perform tasks and follow up on responsibilities, the results of this research will also lose their validity. It would be necessary to conduct a new study in this regard.

Other research limitations in this framework include the type of issues that each province's welfare organization and its employees were involved with. Probably in terms of injuries, the situation in this province was different from other provinces. Therefore, the expected competencies of welfare staff in the province may have been different from those in other provinces. Thus, the findings cannot be extended to the whole country.

\subsection{Future Directions}

Suggestions can be presented in three categories under the headings of suggestions based on research results, directions based on researcher experiences, and recommendations to future researchers.

According to the results and findings of this study, we can point to a greater focus on human resource development planning locally. In addition, by presenting the findings to the parent organization, their opinions could be elicited for use in determining human resource development planning conclusions.

The extracted competencies indicate how things are done now or, in other words, the process of doing things. In this regard, it is possible to determine examples and themes related to each competency, their importance for each organizational position in each category, and the desirability of individuals. Hence, these findings could be used in matters such as employee appraisal. The results of reviewing and identifying existing issues and gaps could be used to design and implement remedial and improvement programs, such as training programs and counseling to solve problems or improvements. It is also suggested that research findings in training, extension, or coaching programs be communicated to managers, supervisors, and employees, and that they are consulted for better use of these findings. This could also be done in the form of a research-consulting project.

Regarding improving the research implementation process, it is suggested that more coordination be established between the research project manager and the staff involved in this process. In the form of an introductory program, the objectives of the research project and its implementation could be explained to the participating employees, and they could be encouraged to participate effectively in work. If the organization were ready, research activities could be done more objectively and in experimental methods.

We suppose that the framework examined could be directed by the possibility of connecting to the practices of inclusion. In fact, the exciting question is to discuss how skills in the workplace can help create an inclusive environment.

Employees' competencies are extensive, new questions and issues are raised every day, and new ideas are presented in this regard. By focusing on new management approaches, researchers could identify related questions and issues, and propose and pursue new research projects. Today, processes such as performance management, knowledge management, learning organizations, the strategic development of human resources, organizational learning, and so on could provide a good platform for raising those issues and pursuing relevant research by researchers. Therefore, a researcher could have a better understanding of the approach considered by the organization and the problems and challenges in the field of competencies before entering directly into the subject of job competencies.

Author Contributions: Conceptualization, S.M.D. and S.E.B.; methodology, S.E.B. and F.M.K.; software, F.M.K.; validation, S.P. (Sergey Prosekov) and N.M.; formal analysis, T.S.; investigation, O.V.K.; resources, O.A.T.; data curation, S.M.D.; writing—original draft preparation, E.K.T.; visualization, S.P. (Svetlana Poliakova). All authors have read and agreed to the published version of the manuscript. 
Funding: The research of S.M.D., S.E.B., and O.V.K. was partially funded by the Ministry of Science and Higher Education of the Russian Federation under the strategic academic leadership program "Priority 2030" (agreement 075-15-2021-1333, dated 30 September 2021). N.M. was supported by Plekhanov Russian University of Economics.

Institutional Review Board Statement: Not applicable.

Informed Consent Statement: Not applicable.

Data Availability Statement: Data sharing is not applicable to this article.

Conflicts of Interest: The authors confirm that there are no conflict of interest to declare for this publication.

\section{Appendix A}

Table A1. Matrix of pairwise comparison and weights of competencies related to the healthcare sphere.

\begin{tabular}{|c|c|c|c|c|c|c|c|c|c|}
\hline & Competency & 1 & 2 & 3 & 4 & 5 & 6 & 7 & Weight \\
\hline 1 & Effective communication with others & 1 & 0.3 & 2.2 & 3 & 5 & 1 & 1 & 0.15 \\
\hline 2 & Compiling reports & & 1 & 2.2 & 3.3 & 3 & 1 & 1 & 0.22 \\
\hline 3 & Decision making and problem-solving & & & 1 & 1.6 & 1.5 & 0.26 & 0.23 & 0.07 \\
\hline 4 & Assessment and monitoring of harms & & & & 1 & 1.1 & 0.19 & 0.17 & 0.05 \\
\hline 5 & Planning healthcare interventions & & & & & 1 & 0.15 & 0.19 & 0.04 \\
\hline 6 & $\begin{array}{l}\text { Directing the implementation of } \\
\text { healthcare interventions }\end{array}$ & & & & & & 1 & 0.83 & 0.24 \\
\hline 7 & Evaluation of health interventions & & & & & & & 1 & 0.23 \\
\hline
\end{tabular}

Table A2. Matrix of pairwise comparison and weights of competencies related to the social affairs sphere.

\begin{tabular}{|c|c|c|c|c|c|c|c|c|c|}
\hline & Competency & 1 & 2 & 3 & 4 & 5 & 6 & 7 & Weight \\
\hline 1 & Effective communication with others & 1 & 0.24 & 4.4 & 0.33 & 1 & 1 & 0.3 & 0.09 \\
\hline 2 & Compiling reports & & 1 & 6.5 & 1.2 & 3 & 2 & 0.6 & 0.23 \\
\hline 3 & Decision making and problem solving & & & 1 & 0.19 & 0.26 & 0.3 & 0.2 & 0.03 \\
\hline 4 & Social harm assessment & & & & 1 & 3 & 2.5 & 0.8 & 0.21 \\
\hline 5 & Planning welfare and social interventions & & & & & 1 & 0.77 & 0.2 & 0.07 \\
\hline 6 & Directing welfare and social interventions & & & & & & 1 & 0.4 & 0.10 \\
\hline 7 & $\begin{array}{c}\text { Evaluation of welfare and social } \\
\text { interventions }\end{array}$ & & & & & & & 1 & 0.27 \\
\hline
\end{tabular}

Table A3. Matrix of pairwise comparison and weights of competencies related to the educational and cultural sphere.

\begin{tabular}{|c|c|c|c|c|c|c|c|c|c|}
\hline & Competency & 1 & 2 & 3 & 4 & 5 & 6 & 7 & Weight \\
\hline 1 & Effective communication with others & 1 & 0.63 & 0.53 & 0.17 & 0.15 & 0.2 & 0.1 & 0.03 \\
\hline 2 & Compiling reports & & 1 & 0.77 & 0.22 & 0.22 & 0.33 & 0.2 & 0.05 \\
\hline 3 & Decision making and problem solving & & & 1 & 0.24 & 0.17 & 0.33 & 0.2 & 0.05 \\
\hline 4 & Educational and cultural needs assessment & & & & 1 & 0.56 & 0.61 & 0.4 & 0.15 \\
\hline 5 & Planning educational and cultural interventions & & & & & 1 & 2 & 0.8 & 0.25 \\
\hline 6 & Directing educational and cultural interventions & & & & & & 1 & 0.3 & 0.15 \\
\hline 7 & $\begin{array}{c}\text { Evaluation of educational and cultural } \\
\text { interventions }\end{array}$ & & & & & & & 1 & 0.32 \\
\hline
\end{tabular}




\section{References}

1. Laakso-Manninen, R.; Viitala, R. Competence Management and Human Resource Development: A Theoretical Framework for Understanding the Practices of Modern Finnish Organisations; HAAGA-HELIA University of Applied Sciences: Helsinki, Finland, 2007.

2. McClelland, D.C. Testing for competence rather than for intelligence. Am. Psychol. 1973, 28, 1-14. [CrossRef] [PubMed]

3. Draganidis, F.; Mentzas, G. Competency based management: A review of systems and approaches. Inf. Manag. Comput. Secur. 2006, 14, 51-64. [CrossRef]

4. Brottman, M.R.; Char, D.M.; Hattori, R.A.; Heeb, R.; Taff, S.D. Toward Cultural Competency in Health Care. Acad. Med. 2020, 95, 803-813. [CrossRef] [PubMed]

5. Engseth, E. Cultural Competency: A Framework for Equity, Diversity, and Inclusion in the Archival Profession in the United States. Am. Arch. 2018, 81, 460-482. [CrossRef]

6. Mullin, A.E.; Coe, I.R.; Gooden, E.A.; Tunde-Byass, M.; Wiley, R.E. Inclusion, diversity, equity, and accessibility: From organizational responsibility to leadership competency. Healthc. Manag. Forum 2021, 34, 311-315. [CrossRef] [PubMed]

7. Collins, J. Good to Great: Why Some Companies Make the Leap and Others Don't; HarperCollins: New York, NY, USA, 2016.

8. Niroomand, P.; Ranjbar, M.; BamdadSufi, J. Professional competencies of managers and sustainable development of Pars Energy Special Economic Zone (providing a proposed framework). Hum. Resour. Manag. Oil Ind. 2011, 10, 73-102.

9. Moyer, B.W.; Reed, P. Using Competencies to Build a Successful Organization; DDI: Toronto, ON, Canada, 2002.

10. Boyatzis, R.E. Competencies in the 21st century. J. Manag. Dev. 2008, 27, 5-12. [CrossRef]

11. Goudreau, J.; Pepin, J.; Dubois, S.; Boyer, L.; Larue, C.; Legault, A. A second generation of the competency-based approach to nursing education. Int. J. Nurs. Educ. Scholarsh. 2009, 30, 6. [CrossRef]

12. Boam, R.; Sparrow, P. Designing and Achieving Competency: A Competency-Based Approach to Developing People and Organizations; McGraw-Hill Book: New York, NY, USA, 1992.

13. Hsiao, A.; Wang, Y.; Ma, E.J.; Jin, X. Do culturally competent employees make for happy visitors? The case of a sports event in Australia. J. Hosp. Tour. Manag. 2021, 49, 624-634.

14. Berg, V.; Birkeland, J.; Nguyen-Duc, A.; Pappas, I.O.; Jaccheri, L. Achieving agility and quality in product development-an empirical study of hardware startups. J. Syst. Softw. 2020, 167, 110599. [CrossRef]

15. Faulks, B.; Song, Y.; Waiganjo, M.; Obrenovic, B.; Godinic, D. Impact of Empowering Leadership, Innovative Work, and Organizational Learning Readiness on Sustainable Economic Performance: An Empirical Study of Companies in Russia during the COVID-19 Pandemic. Sustainability 2021, 13, 12465. [CrossRef]

16. Abdoulaye, B. Research on the Relationship between Human Resource Management Practices and Employee Retention in Chinese Overseas Enterprise Evidence from Huawei in Senegal. J. Int. Bus. Res. Mark. 2018, 3, 7-22.

17. Liang, Z.; Howard, P.F.; Leggat, S.; Bartram, T. Development and validation of health service management competencies. J. Health Organ. Manag. 2018, 32, 157-175. [CrossRef] [PubMed]

18. Geng, Y.; Zhao, L.; Wang, Y.; Jiang, Y.; Meng, K.; Zheng, D. Competency model for dentists in China: Results of a Delphi study. PLoS ONE 2018, 13, e0194411. [CrossRef] [PubMed]

19. Perera, S.; Babatunde, S.O.; Zhou, L.; Pearson, J.; Ekundayo, D. Competency mapping framework for regulating professionally oriented degree programmes in higher education. Stud. High. Educ. 2017, 42, 2316-2342. [CrossRef]

20. El-Zarka, S. Designing a Competency Framework for Logistics Executives: The Case of the Ready-Made Garments Manufacturers in Egypt; University of Huddersfield: Huddersfield, UK, 2010.

21. Skorková, Z. Competency models in public sector. Procedia-Soc. Behav. Sci. 2016, 230, 226-234. [CrossRef]

22. Hamid, A. Development of an HR practitioner competency model and determining the important business competencies: An empirical study in Malaysia. Int. J. Manag. Excell. 2014, 3, 446-461. [CrossRef]

23. Palea, A. The Public Relations Professional. Elements of Identity. Prof. Commun. Transl. Stud. 2014, 7, 17-22.

24. Fang, C.-H.; Chang, S.-T.; Chen, G.-L. Competency development among Taiwanese healthcare middle manager: A test of the AHP approach. Afr. J. Bus. Manag. 2010, 4, 2845-2855.

25. Pillay, R. Defining competencies for hospital management: A comparative analysis of the public and private sectors. Leadersh Health Serv. 2008, 21, 99-110. [CrossRef]

26. Stefl, M.E. Common competencies for all healthcare managers: The healthcare leadership alliance model. J. Healthc. Manag. 2008, 53, 360-373. [CrossRef] [PubMed]

27. Shewchuk, R.M.; O'Connor, S.J.; Fine, D.J.; Tyler, J.L. Building an understanding of the competencies needed for health administration practice. J. Healthc. Manag. 2005, 50, 32-47. [CrossRef] [PubMed]

28. MacKinnon, N.J.; Chow, C.; Kennedy, P.L.; Persaud, D.D.; Metge, C.J.; Sketris, I. (Eds.) Management Competencies for Canadian Health Executives: Views from the Field; Healthcare Management Forum; SAGE Publications Sage CA: Los Angeles, CA, USA, 2004.

29. Saaty, T.L. What is the analytic hierarchy process? In Mathematical Models for Decision Support; Springer: Berlin/Heidelberg, Germany, 1988; Volume 48, pp. 109-121.

30. An, J.; Mikhaylov, A.; Jung, S.-U. A Linear Programming Approach for Robust Network Revenue Management in the Airline Industry. J. Air Transp. Manag. 2021, 91, 101979. [CrossRef]

31. Mikhaylov, A. Development of Friedrich von Hayek's theory of private money and economic implications for digital currencies. Terra Econ. 2021, 19, 53-62. [CrossRef] 
32. An, J.; Mikhaylov, A.; Richter, U.H. Trade War Effects: Evidence from Sectors of Energy and Resources in Africa. Heliyon 2020, 6, e05693. [CrossRef]

33. Lawshe, C.H. A quantitative approach to content validity. Pers. Psychol. 1975, 28, 563-575. [CrossRef]

34. Waltz, C.F.; Bausell, R.B. Nursing Research: Design, Statistics, and Computer Analysis; FA Davis Company: Philadelphia, PA, USA, 1981.

35. Zeraati, M.; Alavi, N.M. Designing and validity evaluation of quality of nursing care scale in Intensive Care Units. J. Nurs. Meas. 2014, 22, 461-471. [CrossRef]

36. Mansfield, R. Practical Questions in Building Competency Model; Workitect Inc.: Fort Lauderdale, FL, USA, 2006 ; pp. 1-18.

37. Barykin, S.Y.; Kapustina, I.V.; Kalinina, O.V.; Parshukov, A.; Aleksandrov, I.; Poberezhnaya, V.M.; Overes, E. The career choice motivation in view of Maslow's hierarchy in innovative economy: The case of Russia. Acad. Strateg. Manag. J. 2021, $20,1-17$.

38. Barykin, S.Y.; Kapustina, I.V.; Valebnikova, O.A.; Valebnikova, N.V.; Kalinina, O.V.; Sergeev, S.M.; Camastral, M.; Putikhin, Y.Y.; Volkova, L.V. Digital technologies for personnel management: Implications for open innovations. Acad. Strateg. Manag. J. 2021, $20,1-14$.

39. Fedorova, E.S.; Naumov, K.V.; Kalinina, O.V.; Sedyakina, A.A. The development of integrated approaches to talent management in the organization. IOP Conf. Ser. Mater. Sci. Eng. 2020, 940, 012103. [CrossRef]

40. Ramírez-Montoya, M.S. Challenges for Open Education with Educational Innovation: A Systematic Literature Review. Sustainability 2020, 12, 7053. [CrossRef] 